\title{
Why IM Me? I'm Right Here!
}

\author{
By Sara Marcus, Queens College
}

\begin{abstract}
Although the relationship between styles of learning and reference service has been taken for granted within the profession, there has been little empirical research that directly links individual learning styles to optimal reference behaviors. This paper is a call for such research, and illustrates the importance of understanding the relationship between individual learning styles and reference service by discussing five of Gardner's styles of learning that are especially important within the reference service context kinesthetic, visual, auditory, intrapersonal, and interpersonal.
\end{abstract}

Within the literature, there has been a long standing relationship between learning styles and reference information behavior (Dalrymple, 2002; Mestre, 2006). However, the nature of the dynamics of this relationship, the important variables, and their consequences has not been studied sufficiently. Although this relationship between styles of learning and reference service has been taken for granted within the profession, there has been little empirical research that directly links individual learning styles to optimal reference behaviors. This paper is a call for such research, and illustrates the importance of understanding the relationship between individual learning styles and reference service by discussing five of Gardner's styles of learning that are especially important within the reference service context kinesthetic, visual, auditory, intrapersonal, and interpersonal.

Think of a reference librarian - or any librarian who is sitting behind a desk. As Carmichael noted in 2007, "more often than not, you will see the image of an old, gray-haired lady with a tight bun in her hair, reading glasses hanging off her nose, and poised in the ssh! position, complete with pointer finger to pursed lips" (40). Think of this librarian performing her duties at the reference desk with a patron. What do you see? Probably the librarian physically leading the patron to the item on the shelves. This is an example of a kinesthetic / visual learning experience, where the patron is physically walking to the item, and visually seeing where the item is located. Toss in the librarian explaining what she is doing, and you also have the auditory and interpersonal learning occurring. Yet, this model using very interpersonal experience might not be best for all. Some learners might prefer to be alone, not making physical contact with a human librarian. Some learners might not want to be physically involved, or some might want to experience the search, finding, and evaluation on their own. Others might want to hear more about what is happening, or might want to see the steps laid out visually, and this may vary over contexts and tasks.

Should the reference librarian decide on just a few of the learning styles to address, ignoring others - and thereby ignoring the needs of some of their clientele; or should they address all learning styles, overloading patrons with information in a wide range of formats? It has been established that not everyone learns in the same way, and understanding this is the first step towards preparing students to become information literate, or literate in any knowledge base (Chau, 2006). Perhaps the best answer is to offer a variety of formats that repeat the information, allowing the patron to select the appropriate method(s) for their individual situation (Burd \& Buchanan, 2004; Mestre, 2006; Neumann, 2003).

As Meredith said in 1999, "In this day of instant gratification, try to slow down. Stop to smell the roses, they will not be there very long. Savor the research and communication process" (19). Try to find out what is the best style to use when instructing the patron, which will best suit them? Often the patrons themselves might not be aware, but by carefully watching and interacting at the start, while determining the true question, the reference librarian can also take note of the best way the patron learns and takes in information (Brown, Murphy, \& Nanny, 2003).

Of course, with the addition of technology, there is the added difficulty of the elimination of some of the very learning styles that we hold dear. How can reference librarians use visual or auditory learning with a patron who cannot see or hear us? How do they deal with the patron who does not like to use 
interpersonal or visual learning? For some patrons, a picture truly is worth a thousand words, and showing them what to do and/or how to do it - be it in person or through handouts with images / screen captures - is the best way to provide the information in a means best suited to their learning style.

As Partridge and Hallam noted in 2006, "a whole new generation - the millennial generation - of learners is now entering higher education, challenging universities to do things differently" (401). This new generation is causing educators, including those behind the reference desk, to reconsider how they present information to those on the other side of the hypothetical desk, be it in a classroom or a library setting. At the least, Millennials are digital natives who tend to be social, experiential multitaskers.

As Piazza stated in 2001, the educator / librarian needs to be aware of the individual patron - their preferred learning style, their culture, their abilities, in order to best be able to serve that individual patron and make their experience an effective one (Shirley, 2003). Should one teach in the method most familiar, usually in front of a classroom speaking (verbal / auditory), possibly with handouts or a projector (visually), or should it be hands-on in a lab and/or the library (kinesthetic)? Should the learning activity be design so that students are working in groups (interpersonal) or working alone (intrapersonal)? What about providing the materials for those who prefer to learn alone with only the computer or a piece of paper to guide them?

Despite the appearance of technology to remove the very attributes valuable in interactions - the nonverbal cues such as gestures, body language, tone of voice - there are benefits to using technology. There is the ability to see the words rather than hear them, to possibly have a written transcript available to 'see' rather than hear. Creating online tutorials enable a user to view the materials at their own speed, and follow along as they need. Including audio narration can enable the auditory learner to gain from the material as well. Handouts - both online and in the library - can enable users to 'teach themselves' or refresh their memories without having to ask questions - something few of us enjoy doing.

As noted by Costello, Lenholt and Stryker (2004), the challenge before reference librarians is recognizing diverse learning styles - both in online and face-to-face environments. This paper does not intend to indicate that the traditional library instructional setting should be abolished. Far from it. Rather, the librarian should consider alternative - not replacements - for the traditional bibliographic instruction (Burd \& Buchanan, 2004; Collinson \& Williams, 2004) in order to serve the widest range of learning styles presented by today's students and that these learning styles may be flexible rather than static, subject to prior knowledge, tasks, or subject. Matching student learning and media preferences provides a rich arena for research in reference delivery methods.

\section{References}

Brown, C., Murphy, T., \& Nanny, M. (2003). Turning techno-savvy into info-savvy: Authentically integrating information literacy into the college curriculum. Journal of Academic Librarianship, 29(6), 386-398.

Burd, B., \& Buchanan, L. (2004). Teaching the teachers: Teaching and learning online. Reference Services Review, 32(4), 404-412.

Carmichael, M. (2007). More tips and tactics. Teacher Librarian, 34(3), 40-42.

Chau, M. (2006). Connecting learning styles and multiple intelligence theories through learning strategies: An online tutorial for library instruction. Library and Information Science Research Electronic Journal 16(1). Retrieved 28 February, 2007, from http://libres.curtin.edu.au/libres16n1/Chau.htm

Collinson, T., \& Williams, A.. (2004). The alternative library. Aslib Proceedings: New Information Perspectives, 56(3), 137-143.

Costello, B., Lenholt, R., \& J. Stryker, J. (2004). Using Blackboard in library instruction: Addressing the learning styles of generations $X$ and $Y$. The Journal of Academic Librarianship, 30(6), 452-460.

Dalrymple, C (2002). Perceptions and practices of learning styles in library instruction. College \& Research Libraries, 63(3), 261-273.

Mestre, L. (2006). Accommodating diverse learning styles in an online environment. Reference \& User Services Quarterl,y 46(2), 27-32. 
Meredith, M. (1999). Confronting the styles and needs of an international clientele. Information Outlook, 3(6), 18-22.

Neumann, H. (2003). What teacher-librarians should know about universal design: One size does not fit all. Teacher Librarian, 31(2), 17-20.

Partridge, H. \& Hallam, G. (2006). Educating the millennial generation for evidence-based information practice. Library Hi Tech, 24(6), 400-419.

Piazza, S. (2001). The teacher-librarian as collaborative partner. Teacher Librarian 28(4) 31-34.

Shirley, G. L. (2003). Correctional libraries, library standards, and diversity. JCE, 54(2), 70-74.

Sara Marcus is an Adjunct Assistant Professor at Queens College. Email: saramrofofsky@gmail.com

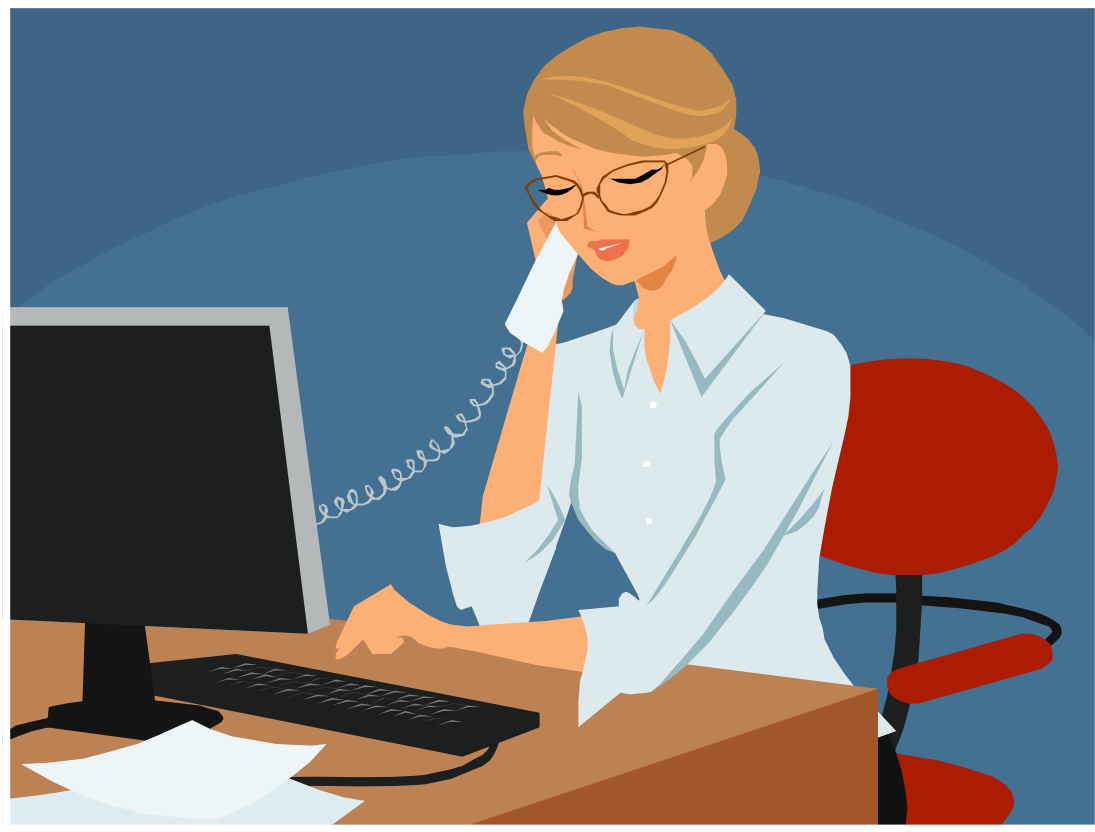

The summer issue will focus on children's resources.

If interested in contributing an article, the deadline is March 15.

Additional book reviewers are also welcome. Email queries and manuscripts to Copy Editor Cybele Werts at cwerts@wested.org

Those interested in reviewing books should contact Review Coordinator Jacqueline Snider at jacqueline.snider@act.org 